\title{
The Ruled-out Scaphoid Fracture on Computed Tomography Prevalence and the Therapeutic Management of Other Carpal Fractures
}

\author{
Johannes Gossner ${ }^{1, *}$ \\ ${ }^{1}$ Department of Clinical Radiology, Evangelisches Krankenhaus Gottingen Weende, Gottingen, Germany \\ *Corresponding author: Johannes Gossner, Department of Clinical Radiology, Evangelisches Krankenhaus Gottingen Weende, Gottingen, Germany. Tel: +49-55150341762, Fax: +49- \\ 55150341124, E-mail: johannesgossner@gmx.de
}

Received: January 26, 2014; Revised: August 19, 2014; Accepted: November 1, 2014

Keywords:Carpal Bones; Disease Management; Prevalence

\section{Dear editor,}

Suspicion of scaphoid fracture is a common topic in emergency medicine. If the radiograph is inconclusive, or there are typical symptoms suggestive of a scaphoid fracture despite a negative radiograph, further investigation with cross-sectional imaging is advocated. Because of its availability, computed tomography (CT) is the primary imaging method in most departments. In recent meta-analyses, CT has a pooled sensitivity of $93 \%$ and pooled specify of $99 \%$ to diagnose the scaphoid fracture (1). There are only sparse data about the prevalence of other carpal fractures in patients undergoing imaging the scaphoid with CT after trauma and the therapeutic consequences of these fractures.

A retrospective analysis of 53 patients who underwent CT imaging of the wrist because of a clinically suspected scaphoid fracture was performed, despite a negative initial radiograph. The sample consisted of 36 men and 17 women with a mean age of 31.2 years presenting at our emergency department. All patients were examined between August 2009 and August 2011 using a 16- slice CT scanner (Activion @, Toshiba Medical Systems, Tokyo, Japan) with a slice thickness of $0.5 \mathrm{~mm}$. Data sets were postprocessed on a standard medical workstation (Vitrea $2 ®$, Vital Images, Minnetonka, USA). The scans were primarily reported by four different consultant radiologists. All data sets were reassessed by the author to ensure the correct primary diagnosis. The electronic medical charts of all patients were reviewed. On admission all patients were examined by a board certified hand surgeon, who decided about further treatment. If a fracture was found on imaging, a follow-up was routinely performed after 4-8 weeks and the patients were instructed to present at the emergency department if there were the new pain, pain worsening, limitations in motion or other uncertainties in the further follow-up.
No fractures were identified in 23 patients (43.3\%). A scaphoid fracture was found in 14 patients (26.4\%). Fifteenth patients $(28.2 \%)$ showed other fractures than the scaphoid (Figure 1). In nine out of 15 patients (60\%), only the small flake fractures were found. In 6 patients, more than one carpal bone were affected. The triquetrum was the most affected carpal bone following the scaphoid. Only one patient showed a radio graphically occult fracture of the distal radius. Patients with scaphoid fractures were advised to undergo osteosynthesis to minimize the risk of pseudarthrosis. All patients showing fractures other than the scaphoid were treated conservatively with splinting and none of these patients received osteosynthesis at our hospital immediately or in the follow-up after trauma.

The found prevalence of other carpal fractures than the scaphoid (in $28.2 \%$ of the patients) is higher than previously reported in the literature. Nguyen et al. reported a prevalence of 3.4\% of other carpal fractures than the scaphoid in CT imaging because of the suspected scaphoid fracture (2). They did not further specify the type of CT scanner and the used slice- thickness, but because the data were recorded between 2001 and 2004 , it may be speculated that a scanner with possibility of high-resolution multi planar reconstructions was not available. In a magnetic resonance imaging (MRI) study found in 14 patients (26.4\%). by Brydie and Raby, the carpal fractures other than the scaphoid were found in $5 \%$ of the cases with a suspected scaphoid fracture and negative radiography (3). In another $10 \%$ of the cases, a bone bruise was only found. They also reviewed other MRI studies and found a cumulative prevalence of $6.5 \%$ for other carpal fractures than the scaphoid in studies examining patients with suspected scaphoid fracture. As they used a slice thickness of $3 \mathrm{~mm}$, the small flake fractures were easily missed. In our small study, all the patients showing fractures other than the

Copyright (c) 2014, Kashan University of Medical Sciences. This is an open-access article distributed under the terms of the Creative Commons Attribution-NonCommercial 4.0 International License (http://creativecommons.org/licenses/by-nc/4.0/) which permits copy and redistribute the material just in noncommercial usages, provided the original work is properly cited. 
Figure 1. Computed Tomography of a 27-Year-Old Patient After Trauma With Suspected Scaphoid Fracture and Negative Radiography

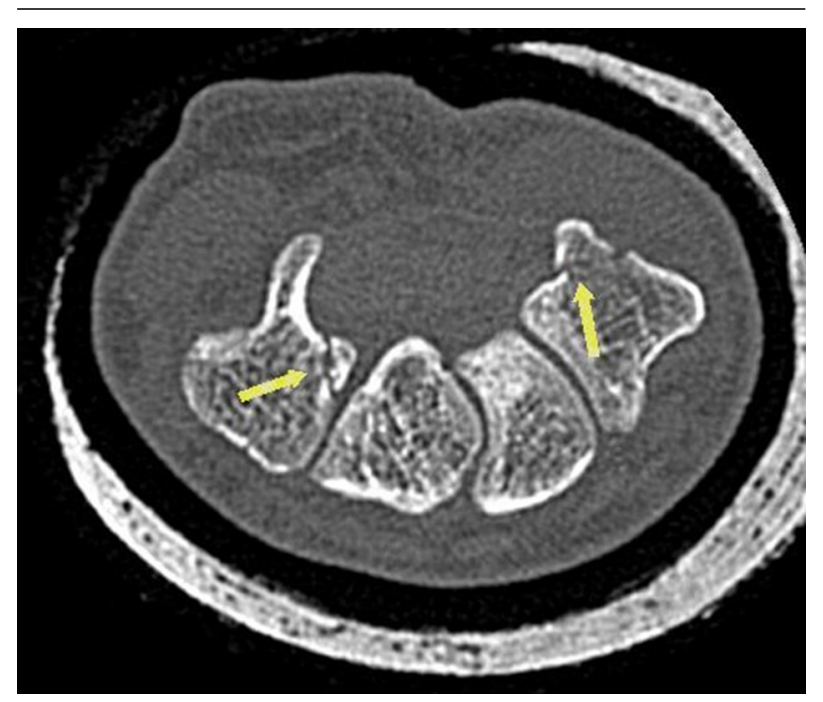

Non-displaced fractures of the trapezium and the hamate can be seen (arrows). These fractures were treated conservatively with splinting.

scaphoid were treated conservatively with splinting and none of these patients received osteosynthesis in our hospital immediately or in follow-up after the trauma. This may be explained by the type of fracture, being either flake fractures or only minimally displaced fractures negative on the conventional radiograph. In the study of Brydie and Raby, most patients with fractures other than the scaphoid and the patients with a bone bruise were only treated with immobilization and splinting. The main limitation of our small study is the retrospective design and therefore the non-structured follow-up, i.e. the long-term outcome could only be estimated. More data from other institutions, preferably in a prospective study with the structured follow-up, are needed before the findings of this study can be generalized.

In conclusion, in a large portion of patients undergoing CT imaging for a suspected scaphoid fracture other carpal fractures can be found. But it seems that these incidentally found fractures can be treated conservatively in most patients.

\section{Acknowledgements}

Parts of this study were presented as a poster at the meeting of German Radiological Society 2012.

\section{References}

1. Yin ZG, Zhang JB, Kan SL, Wang XG. Diagnosing suspected scaphoid fractures: a systematic review and meta-analysis. Clin Orthop Relat Res. 2010;468(3):723-34

2. Nguyen Q, Chaudhry S, Sloan R, Bhoora I, Willard C. The clinical scaphoid fracture: early computed tomography as a practical approach. Ann R Coll Surg Engl. 2008;90(6):488-91.

3. Brydie A, Raby N. Early MRI in the management of clinical scaphoid fracture. BrJ Radiol. 2003;76(905):296-300. 